Title:

\title{
Cannulated bar technology for the orthopaedics: application and processing
}

Authors:

\author{
François Ory (C.E.O.) / Jean-Luc Fraysse (Technical Manager \\ fory@forecreu.com \\ jlfraysse@forecreu.com
}

Presentating Author:

Philippe Veisse (Quality Manager)

pveisse@forecreu.com

Proprietary approach to producing cannulated bars for screws and nails for trauma

- Surgeons' demand

- Cannulated instruments and implants

- Manufacturing cannulated

- Summary

Surgeons' demand

- MIS (Minimally Invasive Surgery) K-wire

- Long bar / small hole technology

- Spec. parameters
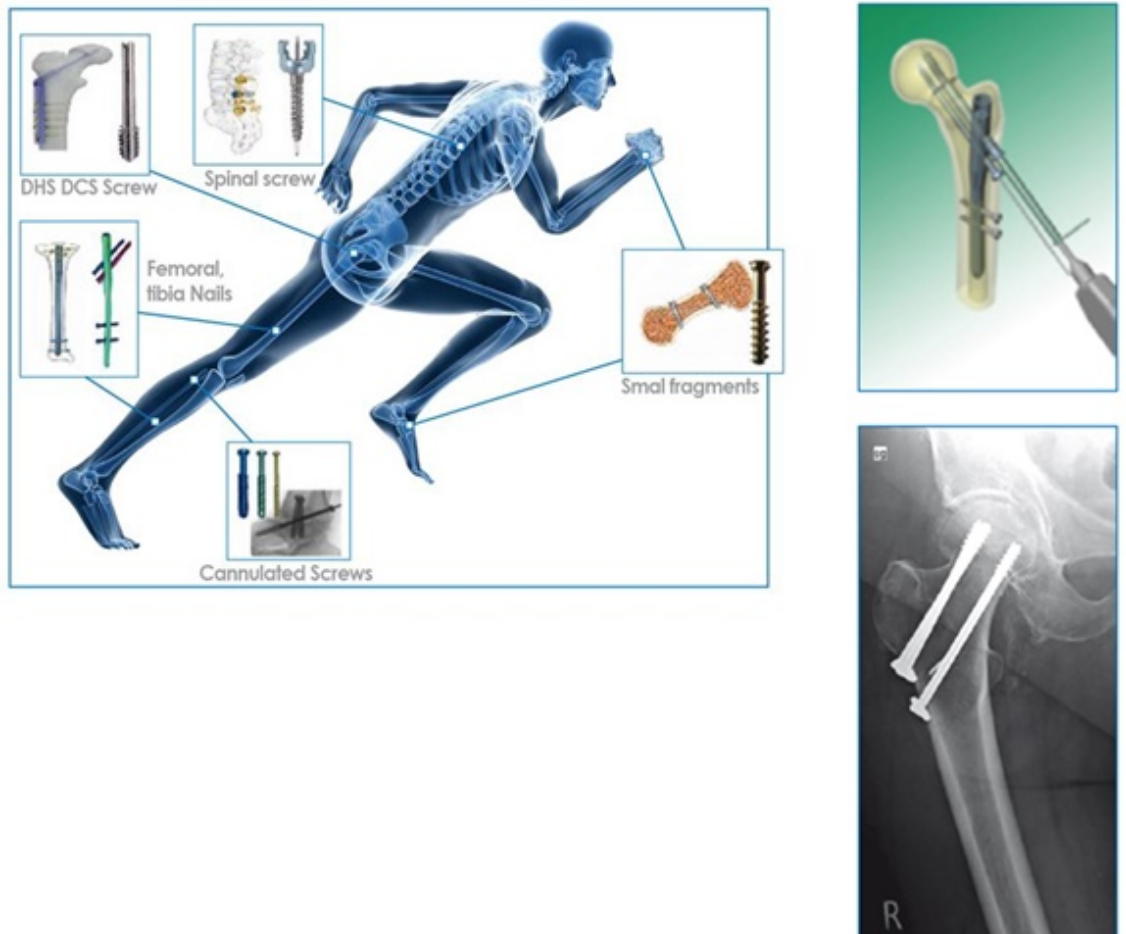

Cannulated instruments and implants

- Instruments: sonotrodes

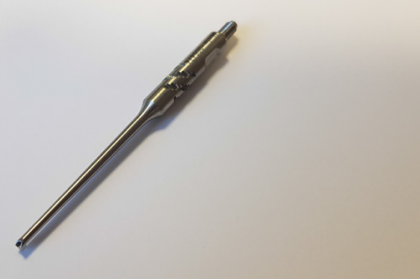

(C) The Authors, published by EDP Sciences. This is an open access article distributed under the terms of the Creative Commons Attribution License 4.0 (http://creativecommons.org/licenses/by/4.0/). 
- Implants: screws, nails
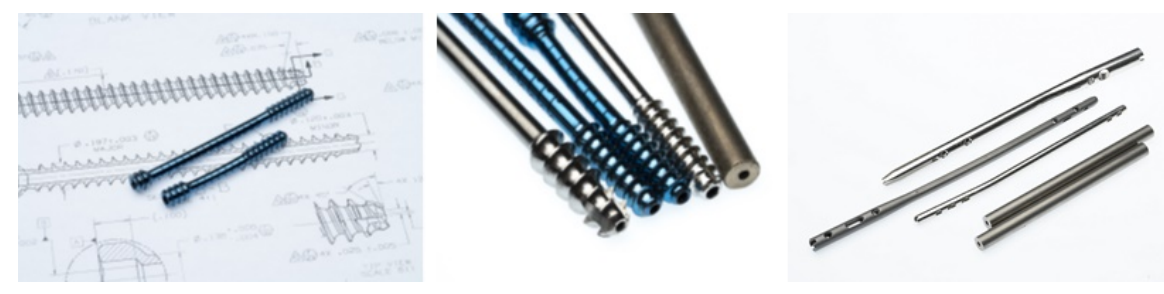

Manufacturing cannulated

Billet and Extrusion

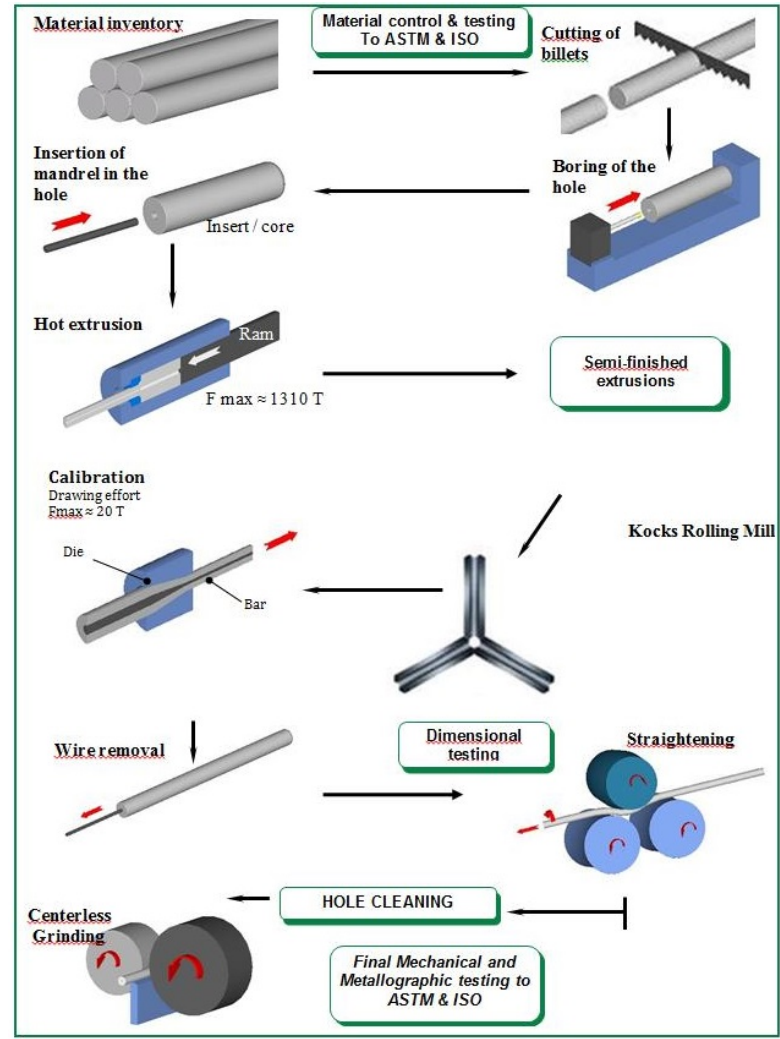

Core material: Same strength at extrusion temperature, highly ductile self-reducing lost core.

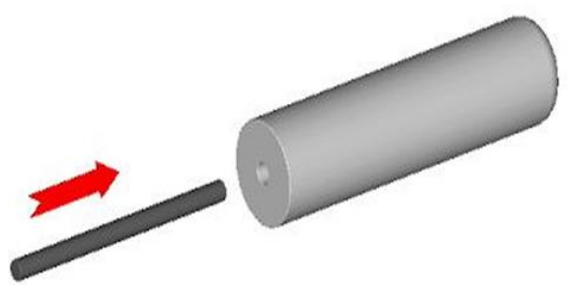

Coating films: Inert material, stop-off membrane, anti-welding prevention, removable, biocompatible.

Hot extrusion press in operation 

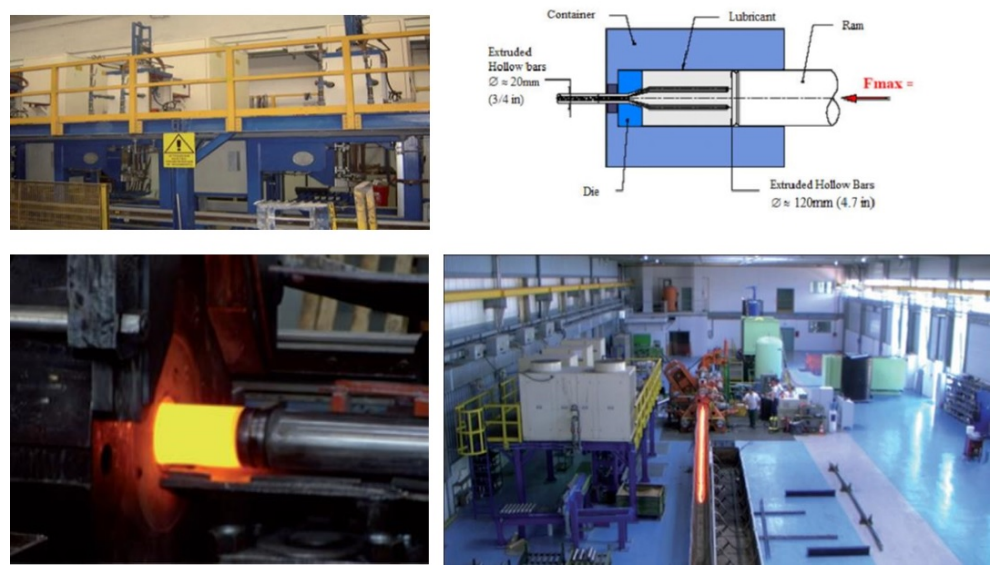

Extrusion: Glass lubricant
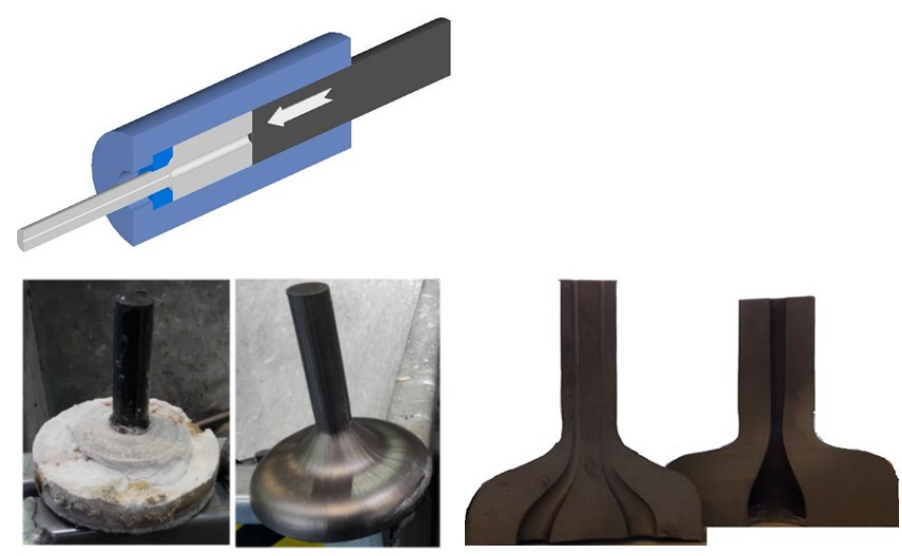

Cold or hot drawing / Heat Treatment / Straightening

KOCKS Rolling:
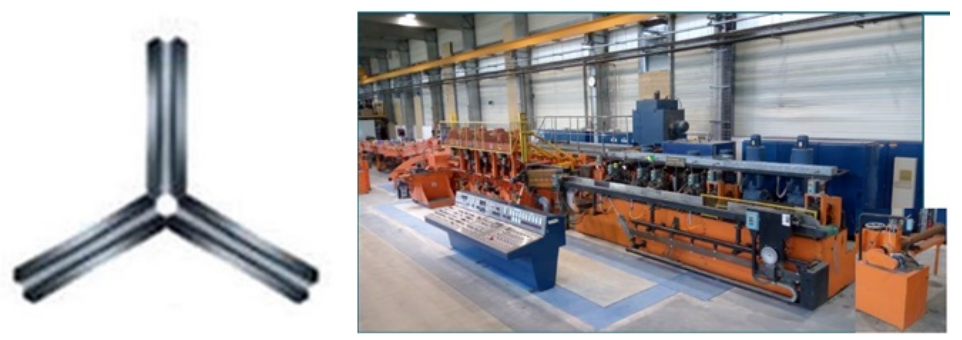

\section{- Existing technologies}

- Selected rolling
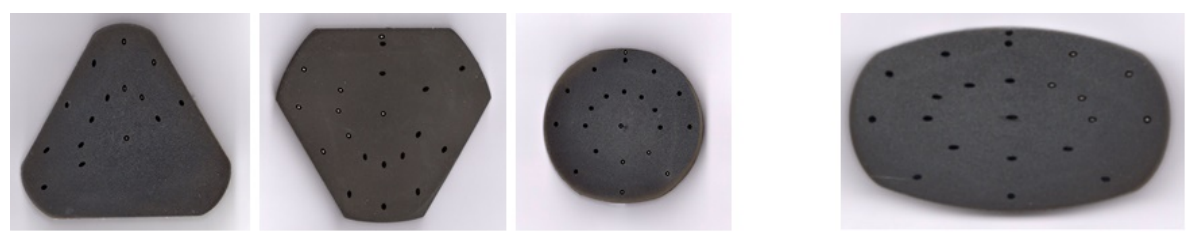

Wire extraction 


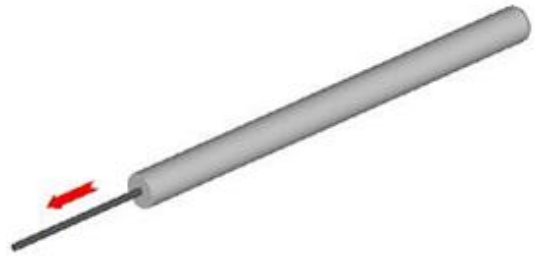

Cleaning and dimensional controls

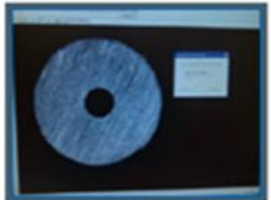

Image Capłure (NOESIS)

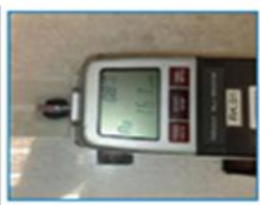

Roughness Control (MITUTOYO)

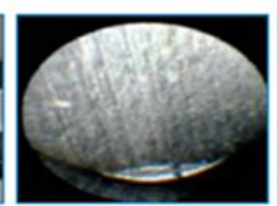

Fibroscopic (CESYCO)

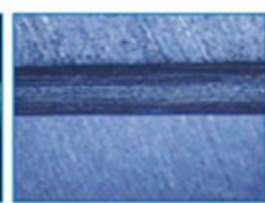

BINOCULAR Image $\times 15$

Metallurgy testing
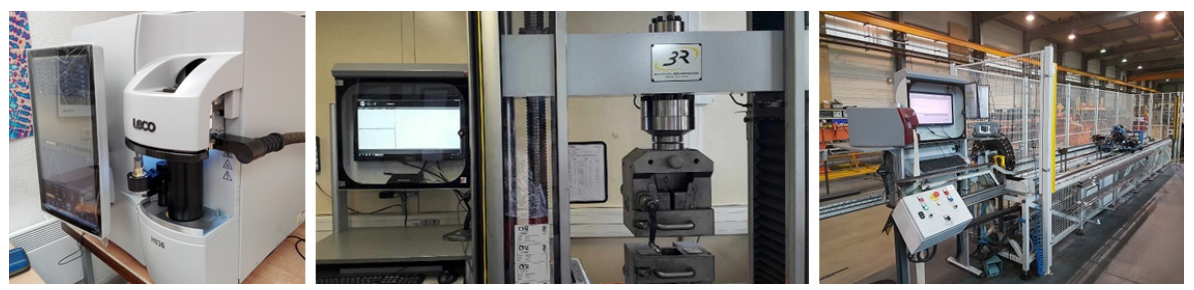

Tensile test

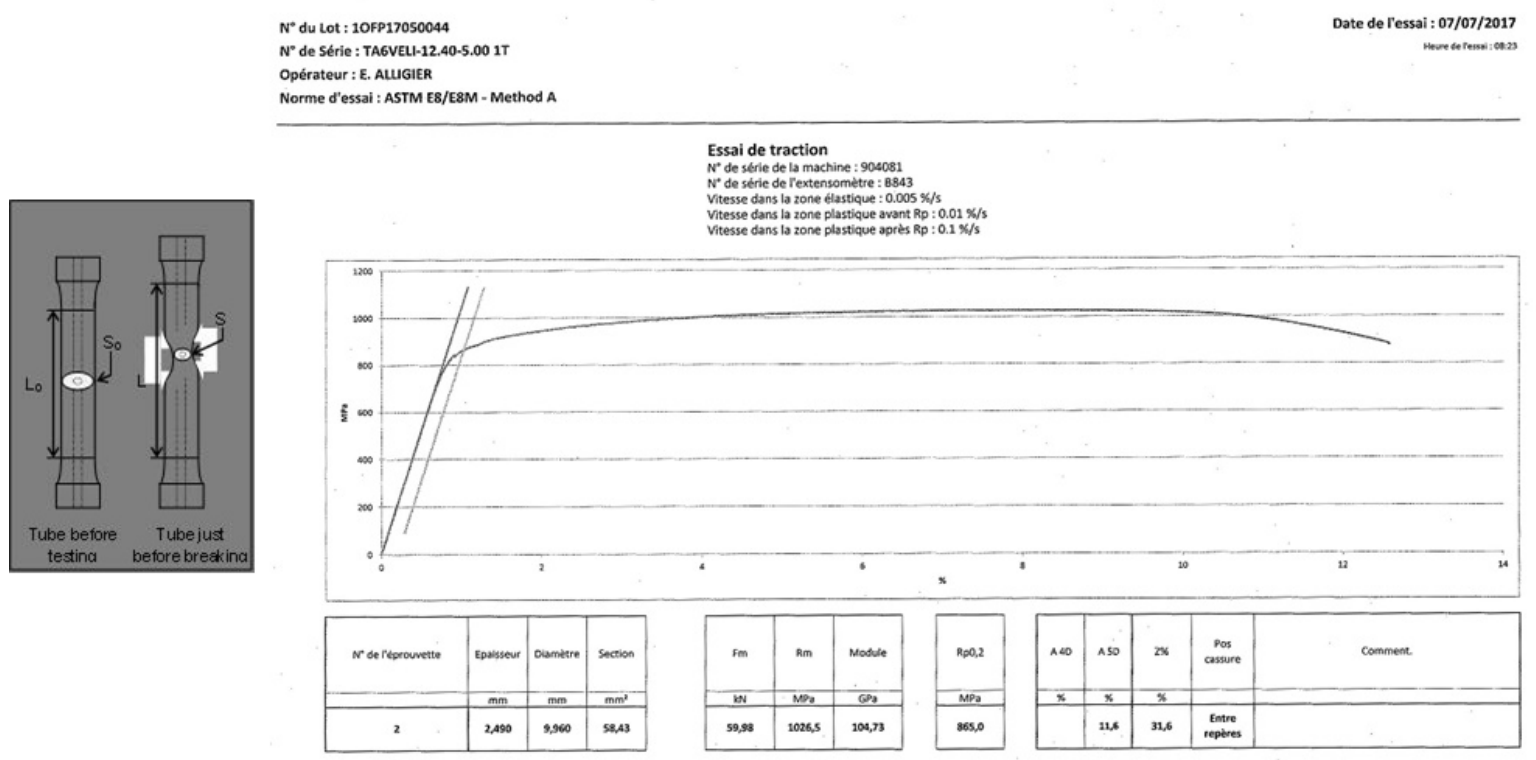

Summary

Surgeons' demand for fracture fixation call for the use of cannulated bars. The mastering of the entire process requests metallurgical expertise as the composite metallic from billet to final bar permanently uses diverse features of alloy properties. Several forging techniques are being used: thanks to glass lubrication, extrusion with axial and hydrostatic compression can take place, then by a triangular axial hot rolling, finally followed by an axial traction with drawing.

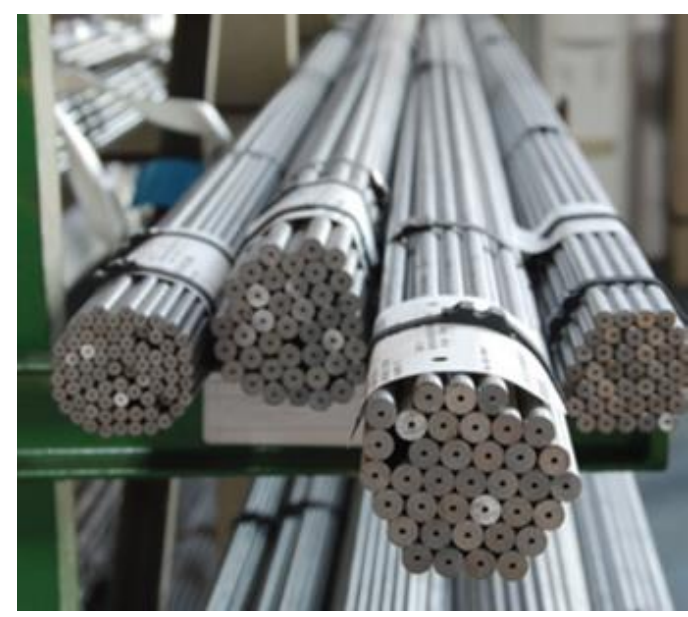

